\title{
The Microwave Spectrum, Structure and Nuclear Quadrupole Coupling Constants for Stibabenzene
}

\author{
Gerald D. Fong, Robert L. Kuczkowski, and Arthur J. Ashe, iII \\ Department of Chemistry, Universily of Michigan, Ann Arbor, Michigan 48109
}

\begin{abstract}
The microwave spectrum of $121-\mathrm{SbC}_{5} \mathrm{H}_{5}, 123-\mathrm{SbC}_{5} \mathrm{H}_{5}, \beta$-dideutero $121-\mathrm{SbC}_{5} \mathrm{H}_{3} \mathrm{D}_{2}$ and $123-\mathrm{SbC}_{5} \mathrm{H}_{3} \mathrm{D}_{2}$ has been assigned in the region $26.5-40.0 \mathrm{GHz}$. The respective rotational constants and uncertainties are: $A=4512.69 \pm 0.42, B=1738.00 \pm 0.01, C=1254.51$ $\pm 0.01 ; A=4512.84 \pm 0.30, \quad B=1729.80 \pm 0.01, \quad C=1250.22 \pm 0.01 ; \quad A=4176.18$ $\pm 0.33, \quad B=1660.94 \pm 0.01, \quad C=1188.15 \pm 0.01 ; \quad A=4176.60 \pm 0.61, \quad B=1652.94$ $\pm 0.03, C=1184.03 \pm 0.03$ (in $\mathrm{MHz}$ units). The structure is found to be planar, $C_{2 v}$ in symmetry. The $d(\mathrm{Sb}-\mathrm{C})=2.050 \pm 0.005 \AA$ and $\angle \mathrm{CSbC}=92.9^{\circ} \pm 1.0^{\circ}$. The nuclear quadrupole coupling constants for the 121 and 123 antimony isotopes are $\chi_{a a}-456.4 \pm 4.1$ $\mathrm{MHz}, \eta=0.396 \pm 0.008$, and $\chi_{a a}=583.00 \pm 5.3 \mathrm{MHz}, \eta=0.399 \pm 0.008$, respectively. Several alternate techniques using the coupling constants as data support a $\sigma$-donating property for antimony.
\end{abstract}

\section{INTRODUCTION}

The properties of benzene together with its heterocyclic homolog pyridine have long served as the primary model for the concept of aromaticity (1). Thus, the recent synthesis of the pyridine congeners phosphabenzene (2), arsabenzene (2), stibabenzene (3), and bismabenzene $(4,5)$ has prompted several experimental and theoretical studies of the bonding properties of these novel heterocycles. Previous experimental work includes gas phase structural determinations for phosphabenzene $(6,7)$ and arsabenzene $(8,9)$, the assignment of the highest occupied MOs of all five of the heterobenzenes $(10,11,12)$ by photoelectron spectroscopy and an analysis of their nmr spectra (13). The dipole moments of phosphabenzene $(6,14)$ and arsabenzene $(9,14)$ as well as the nuclear quadrupole coupling constants of ${ }^{75} \mathrm{As}$ in arsabenzene are known. Theoretical calculations include application of extended $\mathrm{HMO},(9) \mathrm{CNDO} / 2(15,16)$ and ab initio (17) techniques to phosphabenzene and arsabenzene as well as some more sophisticated treatments of phosphabenzene $(18,19)$.

Substantial aromatic character has been attributed to all the heterobenzenes. The assignment of $\pi$-MO levels of phosphabenzene, arsabenzene and stibabenzene by photoelectron spectroscopy suggests similar aromatic bonding patterns in the series $(10,11$, 12). The H-nmr study indicated that part of the downfield shifts experienced by the protons of the $\mathrm{P}, \Lambda \mathrm{s}$, and $\mathrm{Bi}$ congeners could be attributed to an induced diamagnetic ring current (13). The structural studies $(6-9)$ show phosphabenzene and arsabenzene to have planar, $C_{2 v}$ symmetry, while the carbon-carbon bond lengths $(1.40 \pm 0.03 \AA)$ 
are in the aromatic range. Benzene-like structures are thus implied. However, the complete lack of structural data has prevented similar generalizations for stibabenzene and bismabenzene.

We report here the assignment of the microwave spectrum of normal and $\beta$-dideutero ${ }^{121} \mathrm{Sb}$-stibabenzene and ${ }^{123} \mathrm{Sb}$-stibabenzene. Their rotational constants and nuclear quadrupole coupling constants are included and interpretations of these parameters are made in terms of ground state geometry and electronic structure.

\section{EXPERIMEN'TAL DETAILS}

Microwave transitions were measured at room temperature in the region 26.5-40.0 GII $z$ with a Hewlett-Packard $8460 \mathrm{~A}$ microwave spectrometer. The estimatcd unccrtainties of the measured frequencies are $\pm 0.15 \mathrm{MHz}$. The normal species sample was prepared by previously described methods. 3,5-dideutero-stibabenzene was prepared by an adaption of the method previously applied to the synthesis of 3,5-dideuterobismabenzene. Thus, a reaction of 1,4-dihydro-1,1-dibutylstannabenzene-3,5- $d_{2}$ with antimony trichloride gave 1,4-dihydro-1-chloro-stibabenzene-3,5- $d_{2}$, which liberated the desired stibabenzene-3,5- $d_{2}$ when treated with base (DBN) in tetraglyme. Both the normal and deuterated species were stored in tetraglyme at low temperature. Warming to ambient temperature and application of a high vacuum served to liberate the volatile stibabenzene.

Ground state spectrum. The spectrum of stibabenzene is characterized by $\mu_{a}, R$-branch bands containing many weak, close-lying lines. Band centers are spaced at roughly $2.8 \mathrm{GHz}$; individual bands extend over $250 \mathrm{MHz}$ and consist of from 30 to 80 resolvable lines. Assignment in these regions involves consideration of several properties of the hetero atom. The abundances of the two naturally occurring isotopes ${ }^{121} \mathrm{Sb}$ and ${ }^{123} \mathrm{Sb}$ are 57 and $43 \%$. Thus, the observed line patterns are composed of two similar, often interwoven single isotope patterns. Further, the nuclear spins of ${ }^{121} \mathrm{Sb}$ and ${ }^{123} \mathrm{Sb}$ are $\frac{5}{2}$ and $\frac{7}{2}$ respectively so quadrupole coupling is expected to split each hypothetical, spinless transition into a multiplet of lines. Since these quadrupole components are generally spaced from one to five $\mathrm{MHz}$ apart, their Stark effect lobes overlap and partially obscure the hyperfine structure.

The spectrum was finally rationalized by finding distinct, resolvable multiplet patterns located away from any densely packed main band. The spacing between distinct multiplets and the number of resolvable lines in a given multiplet, as well as the line intensity pattern and line spacing in the multiplet were utilized as clues in assignment of the hyperfine lines. Twelve $R$-branch, $a$-type transitions have been assigned for the normal ${ }^{121} \mathrm{Sb}$ isotope and eleven have been assigned for the $\beta$-dideutero ${ }^{121} \mathrm{Sb}$ case. Eight such transitions have also been assigned for both the normal and dideutero ${ }^{123} \mathrm{Sb}$ isotope. (See Tables I and II.) The transition frequencies are the hypothctical, unsplit values $\left(\nu_{0}\right)$ of the absorptions in the absence of nuclear spin. The derived rigid rotor rotational constants, moments of inertia and inertial defects for the four isotopic species of stibabenzene are given in Table III.

Nuclear quadrupole coupling constants. The observed and calculated frequency shifts due to nuclear hyperfine splitting are given for some typical transitions in Tables IV and V. While six or eight major hyperfine lines exist for each 121- or 123-stibabenzene 


\section{TABLE I}

Ground State Transition Frequencies $(\mathrm{MHz})$ for 121 and 123 Stibabenzene

\begin{tabular}{|c|c|c|c|c|c|}
\hline \multicolumn{2}{|c|}{${ }^{121} \mathrm{SbC}_{5} \mathrm{H}_{5}$} & & \multicolumn{3}{|c|}{${ }^{123} \mathrm{SbC}_{5} \mathrm{H}_{5}$} \\
\hline Transition & $v_{0}$ (obs) & & Transition & $v_{0}$ (obs) & $\Delta v_{0}$ \\
\hline $8_{44}-9_{45}$ & 27603.78 & 0.26 & $8_{45}-9_{46}$ & 27290.55 & 0.11 \\
\hline$B_{45}-9_{46}$ & 27410.42 & 0.28 & $9_{27}-10_{28}$ & 31651.04 & 0.11 \\
\hline $9_{46}-10_{47}$ & 30504.91 & 0.19 & $9_{46}-10_{47}$ & 30372.04 & 0.10 \\
\hline $9_{45}-10_{46}$ & 30896.72 & 0.14 & $10_{28}-11_{29}$ & 34430.89 & -0.09 \\
\hline $10_{28}-11_{29}$ & 34558.55 & 0.15 & $11_{39}-12_{3} 10$ & 35604.15 & -0.10 \\
\hline $10_{37}-11_{38}$ & 35407.12 & -0.09 & ${ }^{13} 112-14113$ & 38843.66 & 0.01 \\
\hline $10_{46}-11_{47}$ & 34294.37 & -0.01 & ${ }^{13} 212^{-14} 213$ & 38749.08 & 0.00 \\
\hline $11_{38}-1239$ & 38691.98 & -0.33 & $10_{46}-11_{47}$ & 34126.59 & -0.10 \\
\hline${ }^{12} 58-13_{59}$ & 39815.86 & -0.24 & & & \\
\hline $13212^{-14} 213$ & 38883.14 & 0.01 & & & \\
\hline${ }^{14} 114^{-15} \geq 15$ & 38892.07 & -0.03 & & & \\
\hline $14014^{-15} 015$ & 38893.51 & -0.07 & & & \\
\hline
\end{tabular}

$$
\text { (a) } v_{0}-v(\text { calc) }
$$

transition, many hyperfine lines overlapped so resolution was not always possible. The values of $e Q q_{m}=\chi_{a a}$ and $e Q q_{m} \eta=\chi_{b b}-\chi_{c c}$ were derived by application of a least squares fit of the observed frequency shifts according to Eqs. (6-1) and (6-19) of Ref. (20). The necessary wave function coefficients, $a_{J K}$, were extracted from Beaudet's asymmetric rotor program (21). The derived coupling constants are given in Table VI and were used to obtain the calculated frequencies in Tables IV and V. Only normal species lines were utilized in the fit for $e Q q_{m}$ and $e Q q_{m} \eta$ since no change in the electronic environment or quadrupole axes is expected with deuteration. Further, only a first order treatment of the hyperfine effect was needed to satisfactorily fit the data.

As a measure of the internal consistency of the derived coupling constants, the ratio of the experimentally determined ${ }^{121} \chi_{a a}$ and ${ }^{123} \chi_{a a}$ is computed. The value of 1.277 \pm 0.023 can be compared with the accepted value of $1.27475 \pm 0.00001$ (22). Also, the value of $\eta$ is identical for the two species and the predicted splittings in the deuterated isotopes based on normal species coupling constants match the observed within experimental uncertainty. Both observations are consistent with the assumption of $C_{2 v}$ symmetry for stibabenzene.

\section{ANALYSIS AND DISCUSSION}

Structure. Three structural conclusions are immediately apparent from the spectral observations. First, since no apparent $b$ - or $c$-dipole transitions were found the molecule must have $C_{2}$ symmetry along the $a$ axis. Second, the constancy of the $I_{a}$ for any two species differing only in the antimony isotope indicates that Sb lies on the $a$ axis. Third, the small value of the observed inertial defect is similar to values found for other 
TABLE II

Ground State Transition Frequencies $(\mathrm{MHz})$ for 121 and $123 \beta$-dideuterostibabenzene

\begin{tabular}{|c|c|c|c|c|c|}
\hline \multicolumn{2}{|l|}{$121_{\mathrm{SbC}_{5} \mathrm{H}_{3} \mathrm{D}_{2}}$} & \multicolumn{4}{|c|}{${ }^{123} \mathrm{Sbc}_{5} \mathrm{H}_{3} \mathrm{D}_{2}$} \\
\hline Transition & $v_{o}$ (obs) & $\Delta v_{0}{ }^{(a)}$ & Transition & $v_{0}$ & $\Delta \nu_{0}$ \\
\hline $8_{26}-9_{27}$ & 27439.92 & 0.18 & $8_{26}-9_{27}$ & 27324.33 & 0.00 \\
\hline $8_{35}-9_{36}$ & 27303.76 & 0.22 & $8_{35}-9_{36}$ & 27166.81 & 0.28 \\
\hline $10_{37}-11_{38}$ & 33821.21 & 0.14 & $9_{28}-10_{29}$ & 27040.84 & 0.10 \\
\hline $11_{38}-1239$ & 36900.06 & -0.22 & $11_{47}-1248$ & 36009.39 & -0.08 \\
\hline $11_{47}-1248$ & 36196.39 & -0.12 & $11_{56}-12_{57}$ & 35004.93 & -0.01 \\
\hline $11_{48}-1249$ & 34893.00 & -0.05 & $11_{57}-12_{58}$ & 34822.39 & -0.03 \\
\hline $11_{56}-12_{57}$ & 35171.93 & -0.04 & $11_{48}-1249$ & 34742.54 & -0.10 \\
\hline $11_{57}-12_{58}$ & 34980.73 & 0.00 & ${ }^{12} 66-13_{67}$ & 37666.48 & -0.08 \\
\hline $13_{2} 12-14_{2} 13$ & 36832.74 & -0.04 & & & \\
\hline${ }^{14} 014^{-15} 015$ & 36835.71 & 0.14 & & & \\
\hline${ }^{14}{ }_{1} 14-{ }^{15}{ }_{1} \quad 15$ & 36834.84 & -0.03 & & & \\
\hline
\end{tabular}

(a) $v_{0}-v(\operatorname{calc})$

heterobenzenes and is indicative of a planar molecule. A planar, $C_{2 v}$ symmetry for stibabenzene is thus strongly supported.

A structural description of planar, $C_{2 v}$ stibabenzene requires ten independent, internal parameters, i.e., five hydrogen atom parameters and five ring parameters. Of the twelve measured rotational constants five are independent, so by assuming four hydrogen atom parameters and one ring parameter, the remaining four ring parameters and one hydrogen atom parameter may be extracted. The assumed hydrogen atom parameters are:

\section{TABLE III}

Rotational Constants and Moments of Inertia for the Isotopic Species of Stibabenzene

\begin{tabular}{|c|c|c|c|c|}
\hline & ${ }^{121} \mathrm{SbC}_{5} \mathrm{H}_{5}$ & $123 \mathrm{sbC}_{5} \mathrm{H}_{5}$ & ${ }^{12} 1_{\mathrm{SbC}_{5} \mathrm{H}_{3} \mathrm{D}_{2}}$ & ${ }^{123} \mathrm{SbC}_{5} \mathrm{H}_{3} \mathrm{D}_{2}$ \\
\hline $\mathrm{A} / \mathrm{MHz}$ & $\begin{array}{r}4512.69 \\
\pm 0.42\end{array}$ & $\begin{array}{r}4512.84 \\
\pm 0.30\end{array}$ & $\begin{array}{r}4176.18 \\
\pm 0.33\end{array}$ & $\begin{array}{r}4176.60 \\
\pm 0.61\end{array}$ \\
\hline $\mathrm{B} / \mathrm{MHz}$ & $\begin{array}{r}1738.00 \\
\pm 0.01\end{array}$ & $\begin{array}{r}1729.80 \\
\pm 0.01\end{array}$ & $\begin{array}{r}1660.94 \\
\pm 0.01\end{array}$ & $\begin{array}{r}1652.94 \\
\pm 0.03\end{array}$ \\
\hline $\mathrm{C} / \mathrm{MHz}$ & $\begin{array}{r}1254.51 \\
\pm 0.01\end{array}$ & $\begin{array}{r}1250.22 \\
\pm 0.01\end{array}$ & $\begin{array}{r}1188.15 \\
\pm 0.01\end{array}$ & $\begin{array}{r}1184.03 \\
\pm 0.03\end{array}$ \\
\hline$\kappa$ & -0.703214 & -0.706014 & -0.682394 & -0.685456 \\
\hline$I_{a} / u \AA^{2}$ & 111.99 & 111.99 & 121.01 & 121.00 \\
\hline$I_{b} / u \AA^{2}$ & 290.780 & 292.155 & 304.271 & 305.744 \\
\hline$I_{c} / u \AA^{2}$ & 402.847 & 404.230 & 425.342 & 426.827 \\
\hline$I_{c}{ }^{-I_{a}-I_{b} / u \AA^{2}}$ & 0.077 & 0.085 & 0.061 & 0.083 \\
\hline
\end{tabular}


TABLE IV

Hyperfine Splitting in Stibabenzene (MHz)

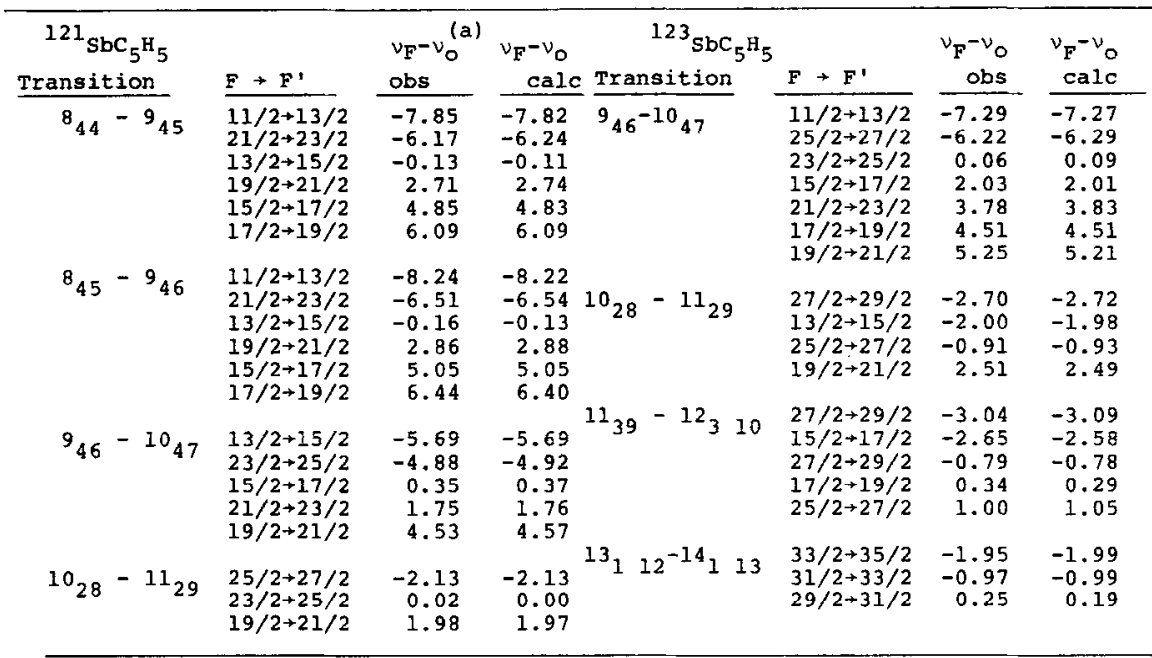

(a) ${ }^{0}$ frequencies listed in Table 1.

$d(\mathrm{C}-\mathrm{H})=1.080 \pm 0.010 \AA$ and $\angle \mathrm{Sb}-\mathrm{C}-\mathrm{H}=117.6 \pm 5.0^{\circ}$. The latter value is similar to those obtained for pyridine, phosphabenzene and arsabenzene (see Table IX). Moreover, the ring parameters are observed to be relatively insensitive to large variations in $\angle \mathrm{Sb}-\mathrm{C}-\mathrm{H}$.

TABLE V

Hyperfine Splitting in Dideuterostibabenzene ( $\mathrm{MHz})$

\begin{tabular}{|c|c|c|c|c|c|c|c|}
\hline${ }^{121} \mathrm{SbC}_{5} \mathrm{H}_{3}$ & $\underline{F} \rightarrow F^{\prime}$ & $\begin{array}{c}v_{F}-v_{O}^{(a)} \\
\text { obs } \\
\end{array}$ & $\begin{array}{l}v_{F}-v_{o}^{(b)} \\
\text { calc } \\
\end{array}$ & ${ }^{123} \mathrm{Sbc}_{5}$ & $\mathbf{F}+\mathbf{F}^{\prime}$ & $\begin{array}{r}v_{F}-v_{0} \\
\text { obs }\end{array}$ & $\begin{array}{l}v_{F}-v_{0} \\
\text { calc } \\
\end{array}$ \\
\hline \multirow[t]{3}{*}{$1_{38}$} & $17 / 2+19 / 2$ & -1.10 & -1.19 & $8_{26}-9_{27}$ & $23 / 2 \rightarrow 25 / 2$ & -3.01 & -2.96 \\
\hline & $25 / 2 \rightarrow 27 / 2$ & -0.01 & -0.01 & & $9 / 2 \rightarrow 11 / 2$ & -1.95 & -2.02 \\
\hline & $19 / 2 \rightarrow 21 / 2$ & 0.73 & 0.79 & & $21 / 2 \rightarrow 23 / 2$ & -1.16 & -1.15 \\
\hline \multirow{7}{*}{$11_{56}-1257$} & $17 / 2+19 / 2$ & -4.79 & -4.83 & $8_{35}-9_{36}$ & $23 / 2+25 / 2$ & -3.95 & -3.88 \\
\hline & $27 / 2+29 / 2$ & -4.17 & -4.21 & & $21 / 2+23 / 2$ & -0.61 & -0.67 \\
\hline & $19 / 2 \nrightarrow 21 / 2$ & 0.34 & 0.34 & $1_{48}-12_{49}$ & $19 / 2+21 / 2$ & -0.49 & -0.49 \\
\hline & $25 / 2+27 / 2$ & 1.43 & 1.45 & & $25 / 2 \rightarrow 27 / 2$ & 3.06 & 3.07 \\
\hline & $21 / 2 \rightarrow 23 / 2$ & 3.36 & 3.36 & & & & \\
\hline & $23 / 2 \rightarrow 25 / 2$ & 3.78 & 3.83 & $11_{56}-12_{57}$ & $15 / 2 \rightarrow 17 / 2$ & -6.12 & -6.09 \\
\hline & $17 / 2 \rightarrow 19 / 2$ & $-5,13$ & -5.04 & & $29 / 2 \rightarrow 31 / 2$ & -5.34 & -5.39 \\
\hline \multirow{4}{*}{$1_{57}-1258$} & $27 / 2+90<2$ & 50 & -5.04 & & $27 / 2 \rightarrow 29 / 2$ & 0.01 & 0.02 \\
\hline & $2172-2972$ & -4.47 & -4.39 & & & & \\
\hline & $25 / 2 \rightarrow 27 / 2$ & 1.52 & 1.52 & & & & \\
\hline & $23 / 2 \rightarrow 25 / 2$ & 4.05 & 4.01 & & & & \\
\hline
\end{tabular}

(a) ${ }^{\circ}$ frequencies listed in Table 2 .

(b) Calculated with constants in Table 6 . 
TABLE VI

Antimony Quadrupole Coupling Constants in Stibabenzene

\begin{tabular}{|c|c|c|}
\hline & ${ }^{12 \mathrm{I}} \mathrm{SbC}_{5} \mathrm{H}_{5}$ & ${ }^{123} \mathrm{SbC}_{5} \mathrm{H}_{5}$ \\
\hline$x_{a a}=e Q q_{a}$ & $\overline{456.4 \pm 4.1 \mathrm{MHz}}$ & $\overline{583.0 \pm 5.3 \mathrm{MHz}}$ \\
\hline$x_{b b}$ & $-137.8 \pm 3.1 \mathrm{MHz}$ & $-175.2 \pm 3.9 \mathrm{MHz}$ \\
\hline$x_{c e}$ & $-318.6 \pm 4.7 \mathrm{MHz}$ & $-407.1 \pm 6.0 \mathrm{MHz}$ \\
\hline$n=\frac{x_{b b}-x_{c c}}{x_{a a}}$ & $0.396 \pm 0.008$ & $0.399 \pm 0.008$ \\
\hline
\end{tabular}

The assumed ring parameter, $\angle \mathrm{C}_{\beta}-\mathrm{C}_{\gamma}-\mathrm{C}_{\beta}$, was fixed at several values in the range $125^{\circ}$ to $130^{\circ}$; the remaining structural parameters were then fitted to the observed moments of inertia using Schwendemann's STRFIT program (23). Some examples of structures calculated for various assumed values of $\angle \mathrm{C}_{\beta}-\mathrm{C}_{\gamma}-\mathrm{C}_{\beta}$ are given in Table VII. The range chosen for $\angle \mathrm{C}_{\beta}-\mathrm{C}_{\gamma}-\mathrm{C}_{\beta}$ is consistent with the observed trend towards larger $\angle \mathrm{C}_{\beta}-\mathrm{C}_{\gamma}-\mathrm{C}_{\beta}$ values for heavier Group $\mathrm{V}$ heterobenzenes (see Table IX). The resultant set of $\mathrm{C}-\mathrm{C}$ lengths in Table VII encompasses the range of $\mathrm{C}-\mathrm{C}$ lengths found in aromatic compounds in general.

In order to further narrow the range of possible structures, several tactics can be applied. It is reasonable to restrict the allowed values of $d(\mathrm{C}-\mathrm{C})$ between $1.38 \AA$ and $1.42 \AA$ in accord with the range of $d(\mathrm{C}-\mathrm{C})$ seen in nearly all benzene derivatives. The range of allowed values of $\angle \mathrm{C}_{\beta}-\mathrm{C}_{\gamma}-\mathrm{C}_{\beta}$ then falls between $129^{\circ}$ and $126^{\circ}$ with a midrange value of $127.5^{\circ}$. Alternatively, one can restrict the range of $\Delta \theta=\angle \mathrm{C}_{\gamma} \mathrm{C}_{\beta} \mathrm{H}-$ $\angle \mathrm{C}_{\beta} \mathrm{C}_{\gamma} \mathrm{H}$. As seen in Table VII, this difference is a strong function of $\angle \mathrm{C}_{\beta}-\mathrm{C}_{\gamma}-\mathrm{C}_{\beta}$. A plausible range for $\Delta \theta$ is $-1.0^{\circ}$ to $+2.0^{\circ}$ in accord with values found in previous Group $\mathrm{V}$ heterobenzenes (Table IX) and in the well studied monosubstituted benzene compounds: fluorobenzene (24), chlorobenzene (25), benzonitrile (26), and aniline (27), where $\Delta \theta$ varies from $0.1^{\circ}$ to $0.54^{\circ}$. The resultant range of $\angle \mathrm{C}_{\beta}-\mathrm{C}_{\gamma}-\mathrm{C}_{\beta}$ then falls between $128.5^{\circ}$ and $127.0^{\circ}$ with a midrange value of $127.75^{\circ}$. By adopting the latter, midrange value for $\angle \mathrm{C}_{\beta}-\mathrm{C}_{\gamma}-\mathrm{C}_{\beta}$ the preferred structure in the last column of Table VII results. The

\section{TABLE VII}

Variation of $\mathrm{SbC}_{5} \mathrm{H}_{5}$ Structure with Assumption for $\mathrm{C}_{\beta} \mathrm{C}_{\gamma} \mathrm{C}_{\beta}$ a

\begin{tabular}{lrrrrrrrrr}
\hline$C_{\beta} C_{\gamma} C_{\beta}$ (ass.) & $125.0^{\circ}$ & $126.0^{\circ}$ & $127.0^{\circ}$ & $127.5^{\circ}$ & $128.0^{\circ}$ & $129.0^{\circ}$ & $130.0^{\circ}$ & $127.75^{\circ}(\mathrm{c})$ \\
\hline $\mathrm{d}(\mathrm{Sb}-\mathrm{C}) \AA$ & 2.046 & 2.047 & 2.049 & 2.050 & 2.051 & 2.052 & 2.054 & $2.050 \pm 0.005 \AA$ \\
$\mathrm{d}\left(\mathrm{C}_{\alpha}-\mathrm{C}_{\beta}\right) \AA$ & 1.371 & 1.383 & 1.394 & 1.400 & 1.405 & 1.416 & 1.426 & $1.40 \pm 0.03 \AA$ \\
$\mathrm{d}\left(\mathrm{C}_{\beta}-\mathrm{C}_{\gamma}\right) \AA$ & 1.427 & 1.414 & 1.401 & 1.395 & 1.389 & 1.377 & 1.367 & $1.39 \pm 0.03 \AA$ \\
$\angle \mathrm{CsbC}$ & $92.19^{\circ}$ & $92.46^{\circ}$ & $92.71^{\circ}$ & $92.83^{\circ}$ & $92.95^{\circ}$ & $93.18^{\circ}$ & $93.40^{\circ}$ & $92.9^{\circ} \pm 1.0^{\circ}$ \\
$\angle \mathrm{SbCC}$ & $125.03^{\circ}$ & $124.53^{\circ}$ & $124.05^{\circ}$ & $123.83^{\circ}$ & $123.61^{\circ}$ & $123.20^{\circ}$ & $122.80^{\circ}$ & $123.7^{\circ} \pm 1.0^{\circ}$ \\
$\mathrm{LC}_{\alpha} \mathrm{C}_{\beta} \mathrm{C}_{\gamma}$ & $126.30^{\circ}$ & $126.17^{\circ}$ & $126.01^{\circ}$ & $125.92^{\circ}$ & $125.83^{\circ}$ & $125.63^{\circ}$ & $125.42^{\circ}$ & \multicolumn{1}{l}{$125.9 \pm 0.5^{\circ}$} \\
$\Delta \theta^{(\mathrm{b})}$ & $-4.90^{\circ}$ & $-2.98^{\circ}$ & $-1.14^{\circ}$ & $-0.24^{\circ}$ & $0.64^{\circ}$ & $2.37^{\circ}$ & $4.06^{\circ}$ & \multicolumn{1}{l}{$0.20^{\circ}$} \\
\hline
\end{tabular}

\footnotetext{
(a) Also assumed are $\mathrm{d}(\mathrm{C}-\mathrm{H})=1.080 \AA$ and $\mathrm{SbCH}=117.6^{\circ}$

(b) $)_{\theta \theta}=\mathrm{c}_{\gamma} \mathrm{C}_{\beta}{ }^{\mathrm{H}}-\mathrm{c}_{\alpha} \mathrm{C}_{\beta}{ }^{\mathrm{H}}$

(c) This set of values with attached uncertainty are preferred by the authors.
} 
TABLE VIII

Variation of $\mathrm{SbC}_{5} \mathrm{H}_{5}$ Structure with Assumption for $d\left(\mathrm{C}_{\beta}-\mathrm{H}\right)^{\mathbf{a}}$

\begin{tabular}{|c|c|c|c|c|c|}
\hline$d\left(C_{B}-H\right) \AA$ (ass.) & 1.040 & 1.075 & 1.080 & 1.084 & 1.120 \\
\hline$a(s b-c) \AA$ & 2.018 & 2.046 & 2.050 & 2.053 & 2.079 \\
\hline$a\left(c_{a}-c_{B}\right) \stackrel{\circ}{A}$ & 3.372 & 1.398 & 1.402 & 1.406 & 1.437 \\
\hline$a\left(c_{B}-c_{\gamma}\right) \&$ & 1.460 & 1.401 & 1.392 & 1.386 & 1.327 \\
\hline$\angle c s b c$ & $90.92^{\circ}$ & $92.66^{\circ}$ & $92.89^{\circ}$ & $93.08^{\circ}$ & $94.59^{\circ}$ \\
\hline$\angle s b c c$ & $129.1^{\circ}$ & $124.4^{\circ}$ & $123.72^{\circ}$ & 123.22 & $119.04^{\circ}$ \\
\hline$\angle c_{\alpha} c_{\beta} c_{\gamma}$ & $121.5^{\circ}$ & $125.4^{\circ}$ & $125.9^{\circ}$ & $126.3^{\circ}$ & $129.7^{\circ}$ \\
\hline$\Delta \theta^{(b)}$ & $-9.48^{\circ}$ & $-0.93^{\circ}$ & $0.20^{\circ}$ & $1.09^{\circ}$ & $8.62^{\circ}$ \\
\hline
\end{tabular}

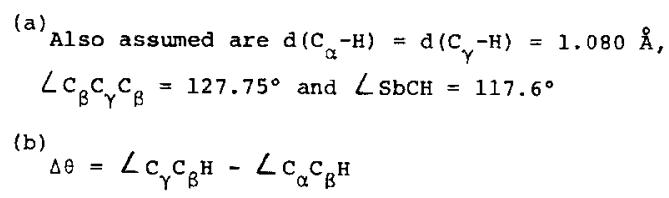

error estimates reflect the extreme range of values the parameters take on within the restrictions of $1.38 \AA \leq d(\mathrm{C}-\mathrm{C}) \leq 1.42 \AA$ and a fixed $d(\mathrm{C}-\mathrm{H})$ distance of $1.080 \AA$.

While the assumption of $d(\mathrm{C}-\mathrm{H})=1.080 \AA$ is a common one, a modest change in one or more of the unique $d(\mathrm{C}-\mathrm{H})$ distances can markedly affect the ring structure. The rapid variation of $\mathrm{C}-\mathrm{C}$ lengths with the angles about the $\beta$-hydrogen suggests in particular, that the assumed value of $d\left(\mathrm{C}_{\beta}-\mathrm{H}\right)$ might be important. Each unique $\mathrm{C}-\mathrm{H}$ distance was therefore varied over the range $1.040-1.120 \AA$ with $\angle \mathrm{C}_{\beta}-\mathrm{C}_{\gamma}-\mathrm{C}_{\beta}$ set to $127.75^{\circ}$, and the remaining two unique $\mathrm{C}-\mathrm{H}$ distances set to $1.080 \AA$. Only trivial changes were observed for any variation of $d\left(\mathrm{C}_{\alpha}-\mathrm{H}\right)$ or $d\left(\mathrm{C}_{\gamma}-\mathrm{H}\right)$. The variation of the derived structure with assumed values of $d\left(\mathrm{C}_{\beta}-\mathrm{H}\right)$ is given in Table VIII.

While the specific values of the structural parameters in Table VIII are dependent on the assumed value of $\angle \mathrm{C}_{\beta}-\mathrm{C}_{\gamma}-\mathrm{C}_{\beta}$ it is evident that as $d\left(\mathrm{C}_{\beta}-\mathrm{H}\right)$ increases, $d\left(\mathrm{C}_{\beta}-\mathrm{C}_{\gamma}\right)$ markedly decreases and $d\left(\mathrm{C}_{\alpha}-\mathrm{C}_{\beta}\right)$ markedly increases. Since data on the monosubstituted benzenes suggests that $d\left(\mathrm{C}_{\beta}-\mathrm{H}\right)$ is in general slightly longer than $1.080 \AA$ the difference between $d\left(\mathrm{C}_{\beta}-\mathrm{C}_{\gamma}\right)$ and $d\left(\mathrm{C}_{\alpha}-\mathrm{C}_{\beta}\right)$ could plausibly be increased from $0.010-$ $0.015 \AA$ if the value of $d\left(\mathrm{C}_{\beta}-\mathrm{H}\right)=1.082 \AA$ is adopted. Under any circumstances, the tentative nature of the preferred structure must clearly be underscored.

The difficulty in choosing the preferred structure in a multi-dimensional solution space of structures when several structure parameters must be simultaneously assumed has led to exploration of Bartell's method of predicate observables (28). This method of structure estimation has been utilized in the test case of difluorophosphine (28) and in a combined microwave and electron diffraction study of phosphabenzene (7). A related "diagnostic" least squares technique has been applied by Curl and Keirns (29) in their study of acryloyl fluoride. As applied to stibabenzene, all twelve available rotational constants are input as "real" observables. Each constant is weighted according to twice the value of their estimated standard deviation. The following nine "predi- 
cate" observables weighted according to the attached range of deviance were additionally used: $d(\mathrm{Sb}-\mathrm{C})=2.045 \pm 0.020 \AA, d\left(\mathrm{C}_{\alpha}-\mathrm{C}_{\beta}\right)=1.400 \pm 0.030 \AA, d(\mathrm{C}-\mathrm{H})=1.080$ $\pm 0.040 \AA, \angle \mathrm{C}-\mathrm{Sb}-\mathrm{C}=94.0 \pm 1.0^{\circ}, \angle \mathrm{Sb}-\mathrm{C}-\mathrm{C}=125.0 \pm 2.0^{\circ}, \angle \mathrm{Sb}-\mathrm{C}-\mathrm{H}=117.5$ $\pm 5^{\circ}$, and $\angle \mathrm{C}_{\alpha}-\mathrm{C}_{\beta}-\mathrm{H}=116.5 \pm 2.0^{\circ}$. The final structure converged to the following values: $d(\mathrm{Sb}-\mathrm{C})=2.048 \pm 0.009 \AA, d\left(\mathrm{C}_{\alpha}-\mathrm{C}_{\beta}\right)=1.408 \pm 0.017 \AA, d\left(\mathrm{C}_{\beta}-\mathrm{C}_{\gamma}\right)=1.387$ $\pm 0.02 \AA, \quad d\left(\mathrm{C}_{\alpha}-\mathrm{H}\right)=1.080 \pm 0.030 \AA, \quad d\left(\mathrm{C}_{\beta}-\mathrm{H}\right)=1.084 \pm 0.016 \AA, \quad d\left(\mathrm{C}_{\gamma}-\mathrm{H}\right)$ $=1.080 \pm 0.030 \AA, \quad \angle \mathrm{C}-\mathrm{Sb}-\mathrm{C}=93.24 \pm 0.30^{\circ}, \quad \angle \mathrm{Sb}-\mathrm{C}-\mathrm{H}=117.6 \pm 3.69^{\circ}, \angle \mathrm{C}_{\alpha^{-}}$ $\mathrm{C}_{\beta}-\mathrm{H}=116.1 \pm 0.02, \angle \mathrm{C}_{\beta}-\mathrm{C}_{\gamma}-\mathrm{C}_{\beta}=127.6 \pm 1.0^{\circ}, \angle \mathrm{C}_{\alpha}-\mathrm{C}_{\beta}-\mathrm{C}_{\gamma}=126.3 \pm 1.0^{\circ}$, and $\Delta \theta=0.74^{\circ}$. Other choices of predicate observable values and weights as well as smaller sets of rotational constants lead to substantially the same final converged structure and fits of observed to calculated inertial moments.

The advantage of the Bartell technique stems from its ability to simultaneously determine the optimum adjusted value of all the predicate observables which reflect the best set of assumptions given the range of attached uncertainties in both the real and predicate observables. In our other structural determinations on stibabenzene, varying the input error estimates on the assumed parameters had no effect; the assumed structural parameters are rigidly frozen. Therein, the "adjustment" of the predicate observables is done piecemeal and by hand, the optimal values being picked by use of intuition and correlations with other known molecular structures. In an ideal case, the results of a predicatc observables analysis should be effectively the same as the preferred structure obtained by fitting the moments for a large range of fixed input assumptions using STRFIT. Such an effective equivalence is observed here with stibabenzene.

The preferred ring structure is consistent with chemical intuition. The $\mathrm{Sb}-\mathrm{C}$ distance of $2.050 \pm 0.005 \AA$ is significantly shorter than the range $2.10-2.25 \AA$ found by electron diffraction and $\mathrm{x}$-ray studies for a variety of tri- and penta-valent organo-antimony compounds $(30,31,32)$. The $\mathrm{Sb}-\mathrm{C}$ length in tris-trifluoro methyl stibine, for example, is $2.21 \pm 0.016 \AA(30)$, a value eight percent longer than in stibabenzene and similar to the nine percent lengthening of the $\mathrm{C}-\mathrm{N}$ bond length found in going from pyridine (33) to trimethylamine (34).

The $\mathrm{C}-\mathrm{Sb}-\mathrm{C}$ angle of $92.9 \pm 1.0^{\circ}$ is in line with trends in the $\mathrm{C}-\mathrm{M}-\mathrm{C}$ angle for the other Group V heterobenzene molecules (see Table IX) and can be compared to the $\mathrm{H}-\mathrm{Sb}-\mathrm{H}$ angle of $91.30 \pm 0.33^{\circ}$ found for stibine (35). The carbon ring angles estimated are also sensible; the relatively large covalent radius of $\mathrm{Sb}$ and the near equivalence of the $\mathrm{C}-\mathrm{C}$ lengths force the $\mathrm{C}-\mathrm{C}-\mathrm{C}$ and $\mathrm{Sb}-\mathrm{C}-\mathrm{C}$ angles towards values greater than $120^{\circ}$ if planarity is to be maintained. Variations of ring angles with heteroatom are given in Table IX.

TABLE IX

Cumparison of Structural Parameters in Group V Heterobenzencs

\begin{tabular}{|c|c|c|c|c|c|c|c|c|c|}
\hline M & $d(M-C) \AA$ & $\mathrm{d}\left(\mathrm{c}_{\alpha}-\mathrm{C}_{\beta}\right) \AA$ & $d\left(C_{\beta}-C_{\gamma}\right) \AA$ & $\angle C M C$ & $\angle M C C$ & $\angle c_{\alpha} c_{\beta} c_{\gamma}$ & $\angle c_{\beta} c_{\gamma} c_{\beta}$ & $\Delta \theta$ & ref \\
\hline$\overline{\mathbf{N}}$ & 1.340 & 1.395 & 1.394 & $116.8^{\circ}$ & $123.9^{\circ}$ & $118.5^{\circ}$ & $118.3^{\circ}$ & $1.12^{\circ}$ & 22 \\
\hline $\mathrm{P}$ & 1.733 & 1.413 & 1.384 & $101.0^{\circ}$ & $124.5^{\circ}$ & $123.8^{\circ}$ & $122.5^{\circ}$ & $0.0^{\circ}$ & 4 \\
\hline As & 1.85 & 1.39 & 1.40 & $97.3^{\circ}$ & $125.1^{\circ}$ & $124.2^{\circ}$ & $124.2^{\circ}$ & $1.4^{\circ}$ & 5 \\
\hline sb & 2.05 & 1.40 & 1.39 & $92.9^{\circ}$ & $123.7^{\circ}$ & $125.9^{\circ}$ & $127.8^{\circ}$ & $0.2^{\circ}$ & this work \\
\hline
\end{tabular}


The data contains a suggestion that the $\mathrm{C}_{\beta}-\mathrm{C}_{\gamma}$ bond length in stibabenzene is about $0.01-0.02 \AA$ shorter than the $\mathrm{C}_{\alpha}-\mathrm{C}_{\beta}$ bond length. A similar shortening of $0.029 \AA$ is observed in phosphabenzene (7). However, the $\mathrm{C}_{\beta}-\mathrm{C}_{\gamma}$ length is reported to be $0.01 \AA$ longer than the $\mathrm{C}_{\alpha}-\mathrm{C}_{\beta}$ length in arsabenzene $(8)$ while they are essentially the same in pyridine (33). It is to be noted, however, that the uncertainties in the $\mathrm{C}-\mathrm{C}$ lengths of both the arsabenzene and stibabenzene are $\pm 0.03 \AA$ and for phosphabenzene they are $\pm 0.015 \AA$. The similar values for $d(\mathrm{C}-\mathrm{C})$ of $1.40 \pm 0.03 \AA$ and the short $d(\mathrm{M}-\mathrm{C})$ in the $\mathrm{P}, \mathrm{As}$, and $\mathrm{Sb}$ are indicative of considerable double bonding character in the ring while the small differences in the two $\mathrm{C}-\mathrm{C}$ bond lengths are suggestive of some electron localization effects. $A b$ initio studies also predict an increasing bond localization for the heavier heterobenzenes even when the assumed $\mathrm{C}-\mathrm{C}$ bond lengths are the same (17).

Nuclear quadrupole coupling constants. The ${ }^{121} \mathrm{Sb}$ coupling constants in Table VI have been used to estimate relative $\mathrm{Sb} 5 p$ populations along the three principal inertial axes. The Townes-Dailey equation in Ref. ( 9 ) has been employed where $q_{0}$, the field gradient for one $p$ electron of the isolated atom, is approximately $650 \mathrm{MHz}$ for ${ }^{111} \mathrm{Sb}(36)$. The resulting relations are: $n_{a}-\left(n_{b}+n_{c}\right) / 2=0.702, n_{b}-\left(n_{a}+n_{c}\right) / 2=-0.212$, and $n_{c}-\left(n_{a}+n_{b}\right) / 2=-0.490$. These relations can be equivalently written as: $n_{a}-n_{b}$ $=0.609, n_{b}-n_{c}=0.185$, and $n_{c}-n_{a}=-0.794$. By symmetry, $n_{a}, n_{b}$, and $n_{c}$ refer to the $p$ orbital populations in the Sb orbitals oriented along the principal inertial axes, where $a$ is along the $C_{2}$ axis and $c$ is perpendicular to the molecular plane. It can be seen that $n_{a}>n_{b}>n_{c}$ as previously found for the $4 p$ populations in arsabenzene $(9)$. We cannot obtain individual values for $n_{a}, n_{b}$, and $n_{c}$ since only two of the equations above are independent. ${ }^{1}$ The relative ordering of the three populations still contains information, however.

The result that $n_{a}$ is largest is consistent with the expectation that the lone pair orbital is formed primarily from the $5 p_{a}$ orbital of Sb. The value of $n_{c}$ is smallest and may plausibly be assumed less than one since antimony is electropositive relative to carbon. This suggests that the $5 p_{c}$ orbital donates electrons to the ring making $\mathrm{Sb}$ a $p_{\pi}$ donor.

It is interesting to compare these conclusions with the orbital populations obtained from Hückel molecular orbital calculations. These calculations were performed using the preferred structure in Table VII. Orbital populations have been determined for various assumed $5 p$ and $5 d$ orbital ionization potentials (VOIP) over the ranges -7.64 to -9.75 and -3.3 to $-7.3 \mathrm{eV}$ respectively. The neutral atom coupling constants predicted by EHMO calculations are: $\chi_{a a}=467 \pm 30 \mathrm{MHz}, \chi_{b b}=-176 \pm 15 \mathrm{MHz}$, $\chi_{c}=-292 \pm 40 \mathrm{MHz}, \eta=0.25 \pm 0.10$.

These predicted coupling constants arc in qualitative agreement with the experimentally determined values. The attached ranges of variance reflect the variance in

${ }^{1}$ It is possible to extract individual populations using a hybridized valence bond scheme described in reference 36, chapter 14. Ignoring $d$-orbital participation and assuming $a_{s}{ }^{2}$ is 0.20 , we obtain the following population estimates : $p_{a}=1.23, p_{b}=0.72, p_{c}=0.53, s=1.49$. The $a_{s}{ }^{2}$ value chosen here is near the value of 0.18 predicted using the electronegativity difference between $\mathrm{Sb}$ and $\mathrm{C}$. While the populations above agree fairly well with EHMO predictions, the choice of $a_{a}{ }^{2}$ is highly arbitrary. If the alternate tactic of extracting it from knowledge of the $\mathrm{C}-\mathrm{Sb}-\mathrm{C}$ angle is used, $a_{z}^{2}$ takes on the value 0.05 which would imply that less than zero electrons occupy the $p$ orbitals! Moreover, even with the chosen value of 0.20 for $a_{s}{ }^{2}$ the calculated charge on $\mathrm{Sb}$ is 1.03 . Such a high charge is suspicious. 
TABLE X

EHMO Orbital Parameters for Antimony

\begin{tabular}{|c|c|c|c|}
\hline atom & Orbital & Exponent & VOIF (eV) \\
\hline H & $1 s$ & 1.200 & -13.60 \\
\hline c & $\begin{array}{l}2 s \\
2 p\end{array}$ & $\begin{array}{l}1.608 \\
1.568\end{array}$ & $\begin{array}{l}-19.42 \\
-10.64\end{array}$ \\
\hline $\mathrm{sb}$ & $\begin{array}{l}5 s \\
5 p \\
5 d\end{array}$ & $\begin{array}{l}2.322 \\
1.999 \\
1.4\end{array}$ & $\begin{array}{l}-16.08 \pm 1.0 \\
-8.64 \pm 1.0 \\
-5.3 \pm 2.0\end{array}$ \\
\hline
\end{tabular}

the VOIP of Table X. The orbital charge distributions suggest the Sb to be both a $\sigma$ and $a \pi$ donor overall.

Several observations preclude any firm conclusions, however. While the TownesDailey equation suggests that the antimony is a $p_{\pi}$ donor it is difficult to estimate whether the $5 d$ orbitals are participating in a donor or acceptor fashion and hence whether the antimony is a $\pi$ donor overall. The necessity for caution is reinforced by the results for arsabenzene $(9)$ where the Townes-Dailey analysis indicated that the arsenic is a $p_{\pi}$ donor in contrast to CNDO (16) and ab initio (17) calculations which concluded that it is a $\pi$ acceptor overall. The origin of this difference has not been resolved.

The EHMO calculations have also indicated that $\mathrm{Sb}$ is a $\pi$ donor. The strength of this conclusion, however, must be similarly tempered since the calculation produces a poor overall charge distribution and predicts symmetries for the highest occupied molecular orbitals in disagreement with those assigned by photoelectron spectroscopy.

Summary. The assignment of four isotopic species of stibabenzene strongly supports a planar, $C_{2 v}$ structure with a clear indication of a shortening of $d(\mathrm{Sb}-\mathrm{C})$ from a single bond and $\mathrm{C}-\mathrm{C}$ bonds close to those in benzene and its derivatives. The carbon ring angles are all greater than $120^{\circ}$ in value. The $\mathrm{C}-\mathrm{Sb}-\mathrm{C}$ angle is near $93^{\circ}$ and is the smallest such angle obscrved so far for the Group V heterobenzene series. Further characterization of the bonding pattern, particularly the extent of differences between the $\mathrm{C}-\mathrm{C}$ distances in the ring must await further spectroscopic or diffraction data. Carbon-13 enriched samples would be very desirable but the present synthesis is too inefficient.

The derived quadrupole coupling constants indicate that $n_{a}>n_{b}>n_{c}$ if the TownesDailey approximation of Ref. ( $(9)$ is followed. Heteroatom $\sigma$ donation is consistent with EHMO and valence bond analyses as well as with simple deductions made from the $p$ orbital population order above. The role of the heteroatom's $\pi$ orbitals needs further study. EHMO calculations performed for a range of assumed orbital parameters were not successful in producing chemically sensible charge distributions although the calculated quadrupole coupling constants were in qualitative agreement with the observed values. Further, more rigorous, quantum mechanical methods are called for before the electronic structure of stibabenzene can be understood.

\section{ACKNOWLEDGMENTS}

This work was supported by Grants CHE76-09572 AO1 and MPS74-17594 from the National Science Foundation. The assistance of Professor L. S. Bartell in the structure calculations is gratefully acknowledged. 


\section{APPENDIX : EHMO CALCULATIONS}

The matrix elements, $H_{i j}$, are calculated according to the recipe: $H_{i j}=0.5 \mathrm{~K}$ $\left(H_{i i}+H_{j j}\right) S_{i j}$, where $K=1.75$. The orbital parameters are given in Table X. The $5 s$ and $5 d$ orbital ionization potentials are estimated by extrapolations of data for the lighter elements in the Group V column. The $5 p$ orbital ionization potential is estimated from free alom spectral data on $\mathrm{Sb}(\mathrm{I})$ found in Moore's tables. All the orbital exponents except the $5 d$ value are taken from reference 37 . The $5 d$ exponent was estimated using Burn's rules (38) and various correlations to the $d$ exponents of As and P. Since, moreover, no previous estimates of optimal VOIP were found for antimony, a series of EHMO calculations were done at various values of the Sb VOIP within the ranges indicated in Table $\mathrm{X}$. Variation of the $5 s$ VOIP caused little change in the electronic population distribution. Variation in the $5 d$ and $5 p$ VOIP gave rise to the range in the predicted coupling constants given in the text. At the midrange VOIP in Table $\mathrm{X}$, the pertinent charge distribution is: $s=1.56, p_{a}=1.22, p_{b}=0.56, p_{c}=0.42$ with no appreciable $d$ orbital participation and a net charge on $\mathrm{Sb}$ of 1.21 . With the $5 d$ VOIP set to $-7.3 \mathrm{eV}$ however, the population distribution showed appreciable $d$ orbital contributions, i.e., $s=1.57, p_{a}=1.19, p_{b}=0.52, p_{c}=0.36$, and $d_{a^{2}}=0.04, d_{b^{2}-c^{2}}=0.07$, $d_{a c}=0.18, d_{b c}=0.17$, and $d_{a b}=0.00$ where the net charge on Sb drops to 0.87 . Increasing the $5 p$ VOIP lead to further charge reduction at the antimony without causing appreciable depopulation of the $5 d$ orbitals. With the $5 d$ VOIP set to $-7.5 \mathrm{eV}$ and the $5 p$ VOIP set to $-7.5 \mathrm{eV}$ the population distribution becomes: $s=1.56, p_{a}=1.28$, $p_{b}=0.67, p_{c}=0.65, d_{a^{2}}=0.05, d_{b^{2}-c^{2}}=0.06, d_{a c}=0.14, d_{b c}=0.19$, and $d_{a b}=0.0$. The net charge on $S b$ is thus 0.39 .

RECEIVED: July 18, 1977

\section{REFERENCES}

1. For additional discussion of aromaticity, see: G. M. Badger, Aromatic Character and Aromaticity, Cambridge Univ. Press, London, 1969 and P. J. Garrett, Aromaticity, McGraw Hill, New York, N.Y., 1971.

2. A. J. Ashe, III, J. Am. Chem. Soc. 93, 3293 (1971).

3. A. J. Ashe, III, J. Am. Chem. Soc. 93, 6690 (1971).

4. A. J. Aste, III, and M. D. Gordon, J. Am. Chem. Soc. 94, 7596 (1972).

5. A. J. AsHe, III, Tetrahedron Lett., 415 (1976).

6. R. L. KuczKowski And A. J. Ashe, III, J. Molec. Siruct. 42, 457 (1972).

7. T. C. Wong and L. S. Barteli, J. Chem. Phys. 61, 2840 (1974).

8. T. C. Wong, A. J. Ashe, III, AND L. S. Barteld, J. Molec. Struct. 25, 65 (1975).

9. R. Lattimer, R. L. Kuczkowski, A. J. Ashe, III, AND A. L. Meinzer, J. Molec. Spec. 57, 428 (1975).

10. C. Batich, E. Heilbronner, V. Hornung, A. J. Ashe, III, D. T. Clark, U. T. Cobley, D. KelCast, and I. W. Scanlan, J. Am. Chem. Soc. 95, 928 (1973).

11. J. Bastide, E. Heilbronner, J. P. Maier, ANd A. J. Ashe, III, Tetrahedron Letl., 411 (1976).

12. A. J. Ashe, III, F. Burger, M. Y. El-Sheik, E. Heilbronner, J. P. Maier, and J. F. Muller, Helv. Chim. Acta 59, 1944 (1976).

13. A. J. Ashe, III, R. R. Sharp, and J. W. Tolan, J. Am. Chem. Soc. 98, 5451 (1976).

14. A. J. Ashe, III and W.-T. Chan, Tetrahedron Lett., 2749 (1975).

15. A. Schweig AND H. OeHLing, Tetrahedron Leti. 56, 4941 (1970).

16. A. Schweig, H. L. HaSe, J. Radloff, ANd H. Hahn, Tetrahedron 29, 475 (1973).

17. D. T. Clark and I. W. Scanlan, J. Chem. Soc. Farad Trans. 70, 1222 (1974). 
18. M. H. Palmer, R. H. Findlay, M. Moyers, and A. L. Gaskeli, J. Chem. Soc. Perkin Trans. II, 841 (1975).

19. W. von Niessen, G. H. F. Diercksen, and L. S. Cederbaum, Chem. Phys. 10, 345 (1975).

20. C. H. Townes and A. L. Schawlow, "Microwave Spectroscopy," Dover Publishing, New York, New York, 1975.

21. R. Beaudet, Ph.D. thesis, Harvard University, 1961.

22. G. H. Fuller And V. W. Cohen, Nuclear Data Tables A5, 483 (1969).

23. R. H. Schwendemann "Critical Evaluation of Chemical and Physical Structure Information," National Academy of Sciences, Washington, D.C., 1974.

24. B. Bak, L. Hansen-NygaArd, and M. J. Rastrup-Anderson, J. Molec. Spec. 2, 209 (1968).

25. F. Michel, P. Nosberger, H. Nery, ANd G. Roussy, J. Molec. Struct. 30, 409 (1976).

26. B. Bak, D. Christensen, W. B. Dixon, L. Hanson-Nygaard, and M. J. Rastrup-Anderson, J. Chem. Phys. 37, 2027 (1962).

27. D. Lister, J. Tyler, J. Høg, and N. W. Larson, J. Molec. Struct. 23, 253 (1974).

28. L. S. Bartell, D. Romanesko, and 'T. C. Wong, "Specialist Periodical Review," The Chemical Society, Vol. 3, Chap. 4. Burlington House, London, 1975.

29. J. J. Ketrns and R. F. Curl, J. Chem. Phys. 48, 3773 (1968).

30. J. M. Bowen, Trans. Farad. Soc. 50, 463 (1954).

31. G. Ferguson, F. C. March, and D. R. Ridley, Acta Cryst. B31, 1260 (1975).

32. J. Kopf, G. Vetter, And G. KLAR, Zeit Anorg. Allgem. Chem. 409, 285 (1974).

33. B. Bak and M. J. Rastrup-Anderson, J. Chem. Phys. 22, 2013 (1954).

34. D. R. Lide and D. E. Mann, J. Chem. Phys. 28, 572 (1958).

35. A. W. Jache, G. S. Blevins, and W. Gordy, Phys. Rev. 97, 680 (1955).

36. W. Gordy and R. L. Cook, in "Chemical Applications of Spectroscopy" (W. West, Ed.), Vol. IX, Chap. 14, Interscience, New York, 1970.

37. E. Clementi and D. L. Raimondi, J. Chem. Phys. 47, 1300 (1967).

38. G. Burns, J. Chem. Phys. 41, 1521 (1964). 